\title{
A Review of the Use of Psychoacoustic Indicators on Soundscape Studies
}

\author{
Margret Sibylle Engel ${ }^{1} \cdot$ André Fiebig $^{2} \cdot$ Carmella Pfaffenbach $^{1} \cdot$ Janina Fels ${ }^{3}$
}

Accepted: 24 June 2021 / Published online: 8 September 2021

(C) The Author(s) 2021

\begin{abstract}
This work reviews the literature of 46 peer-reviewed papers and presents the current status on the use of psychoacoustic indicators in soundscape studies. The selection of papers for a systematic review followed the PRISMA method. Afterwards, descriptive analysis and principal component analysis (PCA) were realised. For the PCA, the following parameters extracted from the papers were analysed: psychoacoustic indicator, hypothesis, statistical units, data collection method and major findings for each investigated psychoacoustic indicator. The results show an overview of the use of psychoacoustic indicators, through main hypothesis and findings for each psychoacoustic indicator i.e. the importance of statistical units, such as percentiles, to investigate the hypothesis related to the description of auditory descriptors and perceptual attributes. Another important finding is that many papers lack the specification of computation methods limiting the comparability of study results and impeding the meta-analyses.
\end{abstract}

Keywords Psychoacoustic indicators $\cdot$ Soundscape $\cdot$ PRISMA model $\cdot$ Principal component analysis

\section{Introduction-Soundscape Research and Psychoacoustics}

Soundscape studies become more and more popular as environmental noise assessment and noise control increasingly adopt the listeners' perspective with their perceptions, the imperative of the soundscape concept [1]. For example, the current noise and soundscape action plan from the Welsh government demands to reduce environmental inequalities by targeting interventions to help those most seriously affected while protecting existing soundscapes that support health and well-being [2]. For those differentiations, improved characterisation of environmental noise is performed by considering

This article is part of the Topical Collection on Noise Pollution

Margret Sibylle Engel

margret.engel@rwth-aachen.de

1 Geography Department, RWTH Aachen University, Aachen, Germany

2 Department of Engineering Acoustics, Institute of Fluid Dynamics and Technical Acoustics, Technische Universität Berlin, Berlin, Germany

3 Institute for Hearing Technology and Acoustics, RWTH Aachen University, Aachen, Germany acoustical quantities, which intend to mimic human auditory sensations [3]. Consequently, the ISO/TS 12913-2 (2018) [4], dealing with soundscape data collection aspects, proposes to measure and report acoustic and psychoacoustic indicators to describe the acoustic environment as the sound from all sound sources modified by the environment and auditory sensations evoked by the sound. The ISO 12913-1 (2014) [5] defines that auditory sensations are influenced by masking, spectral contents, temporal patterns and spatial distribution of the sound sources, which the discipline of psychoacoustics can investigate. These developments led to increased attention to psychoacoustics and its multiple parameters in the realm of soundscape research.

The topic psychoacoustics belongs to the field psychophysics, which investigates systemically how acoustic information is processed by auditory functions [6]. Psychophysics started to be studied in the early nineteenth century when the first perceptual experiments related to the physical world took place to understand the human senses, including hearing [7]. The origin of psychophysics worked with the notion of solely bottom-up signal processing; however, more recent research assumes a combination of bottom-up and top-down processes involved in human perception [8]. Research groups worldwide made significant contributions to the quantitative correlation of acoustic stimuli and auditory sensations in the twentieth century. The paradigm of psychoacoustics is to 
determine functional relationships between acoustic properties and auditory sensation phenomena. As human signal processing is rather complex spectral content, temporal envelopes and periodicities are considered for establishing links between acoustic signals and evoked auditory sensations [9-11]. At the end of the twentieth century with new audio techniques and signal processing capabilities available, the topic psychoacoustic gained additional importance [12] and psychoacoustic parameters characterising specific auditory sensations were increasingly used in the context of preference and valence. Zeitler et al. [13] started to distinguish different concepts about sound quality and sound character. According to Sköld et al. [14], sound character is related to auditory sensations and can be understood 'a parametric representation of sound'. This concept is the basis of psychoacoustics and the description of its indicators, allowing the connection of the physical and perceptual world through parameters such as loudness, sharpness, roughness, tonality and fluctuation strength [15].

The application of psychoacoustic magnitudes to the analysis of the urban sound environment has been less common [3]. In particular, the application of psychoacoustic magnitudes to the perception and assessment of urban sound was mostly limited to laboratory studies in the past. However, over the last 10 years, a progressive increase regarding psychoacoustics in all kinds of soundscape studies is observed. In particular, starting from 2015 , potentially buoyed by the publication of the ISO 12913-1 (2014) [5] introducing the paradigm shift from focusing on the physical exposure to human perception, psychoacoustic aspects were more prominently considered in soundscape studies. This trend seems to continue. However, although increasingly relationships between psychoacoustic properties of acoustic environments and human perception and assessment of those environments are studied, results seem far from being conclusive and generalisable. Although it is clear that the same sound does not create the same response in all individuals due to the probabilistic nature of perception and the contextdependency of sound assessment, sound with its properties elicits auditory sensations related to a certain extent to appraisal [16]. Based on a systematic literature review considering studies investigating soundscapes through psychoacoustics, it is intended to recognise common findings and contradictions.

In the field of classical psychophysics based on a bottomup concept, the link between magnitudes of stimuli and the sensations caused by them is determined and described by mathematical relationships. In the context of psychoacoustics, the connection between acoustic stimuli and auditory sensations is considered in particular. The established psychoacoustic parameters cover a broad range of basic auditory sensations. Loudness is considered to be the most important psychoacoustic quantity describing the perception of volume in detail. Loudness models can be divided into two types [17]: prediction of the perception of loudness (psychoacoustical models) and prediction of physiological response to changes (physiological models). This work focuses on psychoacoustic loudness models, which are implemented into international standards for stationary (DIN 45631, ANSI S3.4-2007, ISO 532 B, ISO 532-2) [18-21] and time-variant sounds (DIN 45631/A1, ISO 532-1) [22, 23]. According to Zwicker [24], the loudness is either computed by means of specific loudness patterns based on the concept of critical bandwidths similar to third-octave bands or, according to Glasberg and Moore [25], using an ERB scale using the concept of equivalent rectangular bandwidths. The psychoacoustic parameter sharpness described the timbre of sounds with special emphasis on highfrequency noise components. The spectral envelope of a sound is responsible for the sensation of sharpness, whereas the fine spectral structure is relatively unimportant in sharpness, according to Fastl and Zwicker [26]. There are three acknowledged models for the calculation of sharpness available, which exhibit either no loudness dependency (DIN 45692, Bismarck model) $[27,28]$ or a certain loudness dependency influencing the impression of sharpness (Aures model) [29]. The psychoacoustics parameters fluctuation strength and roughness model the perception of modulations and adapt to the algorithm, developed by Fastl and Zwicker [26]. A maximum of fluctuation strength is obtained at a modulation frequency of $4 \mathrm{~Hz}$ instead of $70 \mathrm{~Hz}$ modulation frequency for a maximum of roughness [30]. The roughness (hearing model) is a model developed by Sottek [31], which intends to simulate the signal processing of human hearing and judges the roughness of a signal like the human hearing system. The principal calculation methods for tonality are tone-to-noise ratio (TNR), prominence ratio (PR) and spectral flatness measure (SFM) [6], where the prominence of tones within a signal is quantified. Tone-to-noise ratio (TNR) was standardised in the ISO 7729 (2010) [32], which measures the level of a tone compared to the level of the noise within the surrounding frequency band. Prominence ratio (PR) considers the perceived tonality by means of the critical band's power which contains a prominent tonal component and is compared with the mean power of adjacent critical bands [33]. Moreover, further methods for computing a psychoacoustic tonality are currently proposed [34]. Spectral flatness measure (SFM) was developed by Johnston [35]. It is the ratio of the geometric mean $G_{\mathrm{m}}$ to the arithmetic mean $A_{\mathrm{m}}$ of the power spectral of the signal in $\mathrm{dB}$ [35].

This work aims to explore the applicability of established psychoacoustic indicators in soundscape studies through a systematic review of peer-reviewed publications over the last 10 years. Additionally, it will highlight the major findings for each psychoacoustic indicator and intends to indicate further steps for the proper use of psychoacoustic indicators as soundscape descriptors. 


\section{Methods and Materials}

\section{Data Collection Method-PRISMA}

For this study, a broad literature research was realised through search engines like Google Scholar, SCOPUS, Taylor and Francis, Springer, Elsevier, ResearchGate, Academia, journals from the European Acoustic Association and Acoustical Society of America. The work focused on 46 peer-reviewed journal papers published over the last 10 years, which matched the keywords 'psychoacoustic' and 'soundscape'.

It adopted the PRISMA diagram flow as a systemic methodology of data collection [36]. A total amount of identified papers with the keywords 'psychoacoustic and soundscape' revealed 5300 works. After revisions, 64 articles were added, and the total amount of verified works was 5364. An amount of 2336 was identified as duplicates, and they were removed from the amount of 5364, 3038 remained. From this amount, 2998 screen works were excluded due to the requirement of collecting data of journal peer-reviewed work only, which indicated empirical work. Some of the screen works were theoretical, and to be able to consider data collection objectives, only experimental work was selected. After this selection, a total of 40 papers followed the requirements of data collection; even so, one paper was excluded because it was presenting data on merely 'environmental noise' and not any perception of sound i.e. 'soundscape'. Additionally, seven papers were added, which fulfilled the aim of the investigation. At the end of the data collection of this systematic review, this work is presenting 46 peer-reviewed journal papers, which are showing practical works about soundscape combined with psychoacoustic parameters (Fig. 1).

\section{Data Analysis Structure}

This investigation is divided into two parts, (1) an overview description of the investigated studies and (2) a verification of output patterns for each psychoacoustic indicator in soundscape studies.

The first part of the result section shows where the studies occurred (coverage-location), sample size, investigated hypothesis, adopted acoustic and psychoacoustic indicators, applied statistical units of the indicators, the calculation method of the psychoacoustic parameters and data collection method, which is summarised in Annex Table 2, including the reference (author/year). A descriptive analysis of the mentioned data above and other parameters like empirical data collection method (questions and answers format), classified stimuli, sound recording and reproduction is shown in the "3.1 Descriptive Analysis" section.

For the determination of output patterns regarding selected psychoacoustic parameters in soundscape studies, the following parameters were considered: psychoacoustic indicator, hypothesis, statistical units, data collection method and major findings for each investigated psychoacoustic indicator. The observation of patterns was possible through a Principal Component Analysis which is shown in the "Multivariate Analysis" section chapter 3.2.

\section{Post-processing}

Some parameters could be classified into multiple classifications options. To facilitate the data organisation, the adoption of a postprocessing classification was necessary, and, in some cases, existing taxonomy methods were used. The following parameters were post-processed: hypothesis of the investigated studies (classification), major findings of each psychoacoustic parameter (classification) and adopted stimuli (taxonomy methods).

As classification of the hypothesis, it was observed a tendency of concentration of answers on the following classes: 'model construction' (empirical models, perceptual, acoustic and psychoacoustic modelling, geometrical, multivariate model with acoustic properties, sound quality and preferences), 'perceptual attributes' (perceptual attributes and properties, preferences and behaviours such as pleasantness/unpleasantness, eventfulness, annoyance, vibrancy, comfort, background and foreground, disruptive, supportive, calming characteristics), 'relationship between parameters' (objective data - physical environment and design; subjective data - perceptual, cognition and personality traits; economical and methodological), 'soundscape characterisation' (subjective - perceptual, preferences, quality, individual, cognition; objective - physical, spatial, temporal; dimensional; economic; context), 'properties' (objective - physical, spectral, temporal, acoustic, psychoacoustic, spatial; subjective - physiological, psychological, perceptual, behavioural), 'experiments' (listening tests and acoustic virtual reality), 'dimensions' (importance of a soundscape in an environment, preventive soundscape in adverse health environments, conservation of iconic soundscapes, influencing factors of special soundscapes), 'design' (ways to design soundscapes, tools for design, design for economic and environmental benefit, practices of specific locations) and new 'methodology' (spectral features of the sonic environment, automatic soundscape affect). The answers were classified in some cases in multiple classes, according to their characteristics.

The major findings of loudness, sharpness, roughness, fluctuation strength and tonality were also classified and divided into the following classes: 'explanation of auditory descriptors' (sound quality: pleasantness/unpleasantness, eventfulness, valence, annoyance, arousal, arousal, acceptance, satisfaction, tranquillity, harmony; preference; visual aspects; variability; priciness; individuality), 'percentiles' (statistical scores describing the distribution of (psychoacoustic) values), 'correlation with physical descriptors' (acoustic and psychoacoustic parameters, geometrical shape, position, height), 
Fig. 1 PRISMA flow-diagram for soundscape studies and use of analysis psychoacoustic parameters meta-

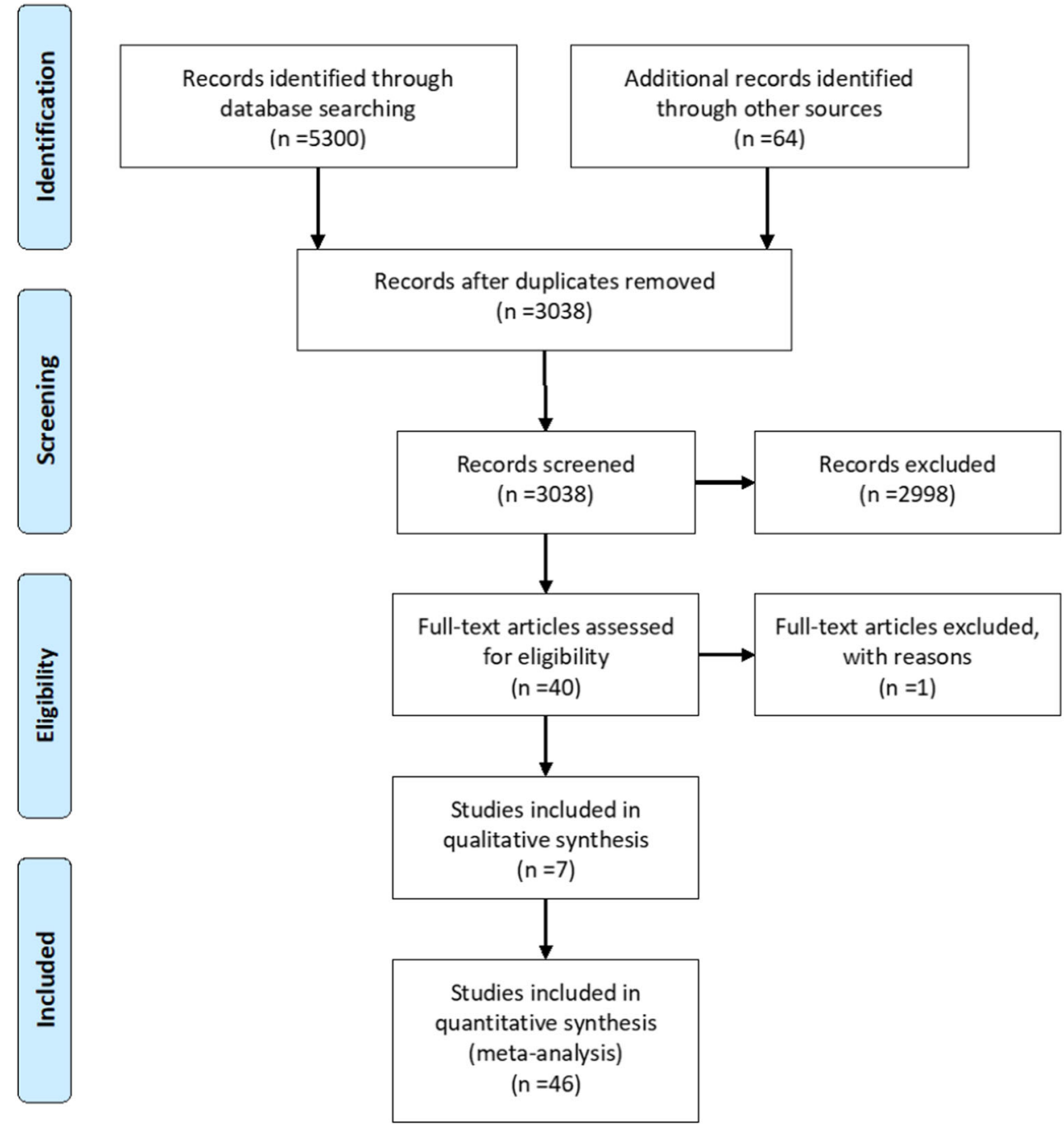

'psychoacoustic quantities for sounds', 'behaviours' (overall human responses, listener distractions) and 'quantity of sound sources'.

Two taxonomy methods for the classification of sound sources were applied regarding the adopted stimuli in each study. The first taxonomy considered was developed by Brown et al. [83] and improved as a taxonomy option described in the ISO 12913-2 [4]. Moreover, the taxonomy method for the classification of sound sources proposed by Schafer [84] was considered.

\section{Results}

\section{Descriptive Analysis}

The investigated studies shown in Annex Table 2 collected data in 44 different locations in five continents. Most of the studies were performed in Europe (58\%) and Asia (30.4\%), whereas only a few studies took place in North America,
South America and Oceania. The sample size of participants within the investigated studies shows a significant variation from 7 to 10,000 persons.

Regarding the hypothesis classification of each investigated study, it was observed that the soundscape studies focused on soundscape characterisation $(21.0 \%)$, relationships (auditory perception, physical, health effects, prices) $(17.1 \%)$, experiments $(15.2 \%)$, properties $(14.3 \%)$, perceptual attributes $(12.4 \%)$, model construction (10.5\%), dimensions and design (3.8\% each) and methodology (1.9\%).

From a sample of 178 observations, which could simultaneously report acoustic and psychoacoustic indicators, only $21.9 \%$ used acoustic indicators. A percentile ${ }^{1}$ value $X$ of a certain parameter is the value that is reached or exceeded in $X \%$ of the measuring time

\footnotetext{
${ }^{1}$ Please note that the interpretation of percentile values in psychoacoustics is inconsistent with the common definition and use of percentile values in statistics, which interpret percentile values as those values that reach or go below the value within the data set. However, the different use of percentile values in the described way is very common and established in psychoacoustics and the authors follow this notion in this paper.
} 
interval $[42,51]$ i.e. the $P_{50}$ corresponds to the median of the psychoacoustic indicator, $P_{10}$ corresponds the value which is exceeded in $10 \%$ of the time, representing events with the greatest magnitudes over time and $P_{90}$ represents the background magnitudes at least reached in $90 \%$ of the measuring time. The difference between 10th and 90th percentiles embody the variability of sound magnitudes over time [51].

Loudness was adopted in $23 \%$ of the studies, followed by sharpness $(21.9 \%)$, roughness (16.3\%), fluctuation strength $(14 \%)$ and tonality $(2.8 \%)$. From 115 observations which could use more than one statistical unit, $36.5 \%$ are using averages as a single representative values, followed by $P_{5}(14 \%)$ $[38,39 \bullet \bullet, 41,50,52,54,55,61,62,65,66 \bullet, 68,72,75,81$, 82], $P_{10}(13 \%)[38,39,41,42,44,46,51,61,65,67,68,70$, 72, 77, 82], $P_{50}(9.6 \%)[38,39,41,42,44,61,65,72,77,81$, 82], $P_{95}[38,39,41,55,61,65,72,75,81,82], P_{10}-P_{90}(8.7 \%$ each) $[42,51,70], P_{90}(7.8 \%)[38,39,41,44,65,68,70,77$, 82] and $P_{1}$ and $P_{99}$ (1\% each [82]).

The most used loudness calculation method $(N=31)$ was the Zwicker method (55\%), which was not further specified. Derivations of the Zwicker model represent together $45 \%$, including the ISO $532 \mathrm{~B}$, DIN 45631/A1, ISO 532-1 and Chalupper and Fastl. For the calculation of sharpness $(N=17)$, the Aures computation method had $47 \%$ and DIN 45692 presented 35\% of adoption; Fastl and Zwicker and Chalupper and Fastl were adopted in $18 \%$ of the cases. Roughness $(N=7)$ was calculated according to Sottek in $71 \%$ of the observations, as well as Daniel and Weber in $29 \%$ of the cases. For the parameter of fluctuation strength $(N=4)$ a computation according to Sottek was used in $100 \%$ of the observations. Tonality was only considered in 5 studies, and the adopted calculation methods were performed according to Zwicker, DIN 45681 and Terhardt and Aures. Surprisingly, a significant number of studies did not specify the calculation methods of the psychoacoustic indicators correctly. A quarter of all considered studies did not specify the used methods and standards for the computation of the respective parameters.

Regarding data collection methods, $36.2 \%$ of the reviewed studies used listening tests or virtual reality experiments. $22.4 \%$ adopted questionnaires or surveys, $12.1 \%$ soundwalks, $10.3 \%$ interviews, $12.1 \%$ acoustic measurements each and one paper worked with a focus group.

The evaluated items shown in Annex Table 2 also investigated how the data collection regarding soundscape perception, adopted stimuli, sound collection, equipment for recording and reproduction, and major findings for each psychoacoustic parameter are represented.

Studies that investigated soundscapes using questions used different scaling formats: verbal scale $(22.6 \%)$, rating scale (16.1\%), semantic differential (14.5\%), open-ended and sociodemographic questions (11.3\% each), visual analogue $(9.7 \%)$, staple scale $(6.5 \%)$, self-assessment manikin, attribute matching, multiple-choice, rank order and dichotomous answers $(1.6 \%$ each). A systematic overview of frequently used empirical methods in soundscape can be found in Engel et al. [85].

As explained in the "Post-processing" section, two taxonomy methods for sound sources (stimuli) classification were adopted. Using the first taxonomy method, the following classification of stimuli was observed: 'nature' (17.9\%), 'social/ communal' (16.6\%), 'voice and instrument' and 'human movement' (15.9\% each), 'motorized transport' (14.5\%), 'electro-mechanical' (11\%), 'domesticated animals' (5.5\%) and 'others' $(2.8 \%)$. For the taxonomy method, according to Schafer (1977), the stimuli were classified in the first level as follows: 'natural sounds' and 'sounds and society' (22.1\% each), 'human sounds' (21.4\%), 'mechanical sounds' (15\%) and 'sounds as indicators' (12.9\%).

Regarding the collection of sound, most studies used outdoor sound recordings (57.8\%) that were not performed during soundwalks. In $20 \%$ of the papers, indoor sound recordings were realised. Only $13.3 \%$ of sounds were collected during soundwalks, and in $8.9 \%$ of the cases, sounds from existing databases were used. In most cases, the sounds were recorded with binaural measurement systems (42.4\%), standalone recording devices with an integrated microphone (16.9\%), sound level metres (15.3\%), stereo microphones (11.9\%), ambisonics $(6.8 \%), 360^{\circ}$ cameras $(3.4 \%)$, cameras and a triaxial acceleration sensor for vibration measurements (1.7\% each). The playback during the listening test was mostly realised via headphones (38.5\%), Oculus and loudspeakers (7.7\% each) and GoPro VR Player (3.8\%).

Concerning the major findings drawn from the soundscape investigations, they were separated according to each psychoacoustic parameter. The major findings could belong to more than one category in each study. For loudness in 46 cases, major findings based on the parameter loudness were obtained, followed by sharpness (30), roughness (19) and fluctuation strength (20). According to the classification of major findings adopted during the post-processing of the raw data, the explanation of auditory descriptors was the most observed major finding for loudness (50\%), sharpness (52\%), roughness (53.3\%) and fluctuation strength $(56.3 \%)$. The second most reported finding was related to (1) quantities of psychoacoustic parameters, as observed in loudness (13\%), sharpness (20\%), roughness (20\%) and fluctuation strength (18.2\%); (2) correlation with other physical descriptors, observed in roughness $(26.7 \%)$, loudness (15.2\%), fluctuation strength (18.8\%) and sharpness (12\%). Related to tonality, there was only three observations of major findings, which were classified with $33.3 \%$ in correlation with physical descriptors, quantities of tonality for sound sources and quantities of sound sources.

\section{Multivariate Analysis}

Before conducting a complete principal component analysis, the following assumptions were accepted: variables with 
continuous level (which was the number of observations of each variable) as observed in Ma et al. [77], linear relationship between variables, sample adequacy through Kaiser-MeyerOlkin (KMO) test, suitability for data reduction and no significant outliers. The observation of the assumption's attendance occurred with the following indicators: loudness, sharpness, roughness and fluctuation strength. For the indicator tonality, it was not possible to follow the assumptions due to the small sample size.

The components extracted for each psychoacoustic indicator are shown in Table 1. Each relevant component loading with values over the cut-off 0.5 is highlighted in grey, indicating the major loadings of each component. Additionally, to confirm the quantity of extracted components, a parallel analysis was conducted through a parallel analysis engine [86], which calculates eigenvalues from randomly generated correlation matrices. These are compared with the eigenvalues from each conducted PCA. Suppose the PCA eigenvalues are larger than the corresponding random eigenvalues. In that case, these should be retained in the analysis [87] (cut-off indicated in dark grey at the 'eigenvalues' and 'randomly simulated eigenvalues' lines).

Seven components were extracted in the loudness PCA, representing $82.6 \%$ of the sum of the squared component loadings. Bartlett's test of sphericity, which tests the overall significance of all the correlations within the correlation matrix, was significant $\left(\chi^{2}(105)=241.175, p<0.001\right)$, indicating that it was appropriate to use the PCA model on this set of data. The Kaiser-Meyer-Olkin measure of sampling adequacy suggested that the relationships amongst variables were high $(K M O=0.47)$; thus, it was acceptable to proceed with the analysis. The parallel analysis indicated that the first two components $(1 \mathrm{~L}$ and $2 \mathrm{~L}$ ) are relevant, which cumulated $36.8 \%$ of the eigenvalues in the components.

As observed in Table 1, the first component for loudness (1L) is composed of percentiles $P_{5}, P_{10}, P_{50}, P_{90}$ and $P_{95}$ with positive loadings. The second component (2L) shows a combination of the hypothesis experiment with positive loadings and data collection through listening tests or AVR with positive loadings and objective measurements with negative loadings.

In the sharpness PCA, six components were extracted with the representation of $74.1 \%$ of the component's loadings. Bartlett's test of sphericity was significant $\left(\chi^{2}(120)=\right.$ $254.841, p<0.001)$ and $\mathrm{KMO}=0.465$, which was acceptable to proceed with the analysis. All six components are relevant according to the parallel analysis results.

As indicated in Table 1, the first component for sharpness (1S) is composed of positive loadings of percentiles $\left(P_{5}, P_{10}\right.$, $P_{50}, P_{90}$ and $\left.P_{95}\right)$. The second component (2S) presents positive component loadings for hypothesis (experiments) and data collection method (focus group and listening tests/ AVR). Negative loadings are observed for the data collection (objective evaluations). The third component (3S) is showing a combination of hypothesis with positive loadings (design) and data collection (soundwalks). In the fourth component (4S), positive loadings of percentiles $\left(P_{10}-P_{90}\right)$ are combined with negative loadings of the hypothesis (methodology) and positive loadings of data collection (focus group). The fifth component (5S) shows negative loadings for the hypothesis (experiments) and positive loadings for data collection (interviews). In the sixth component (6S), there are negative loadings for major findings regarding sharpness (quantities of sharpness for the sound sources).

The roughness PCA results presented seven components which represent $79.1 \%$ of the extracted components. Bartlett's test of sphericity was significant $\left(\chi^{2}(153)=\right.$ $256.71, p<0.001)$ and $\mathrm{KMO}=0.438$, which was acceptable to proceed with the analysis. Only the first two components are relevant according to the parallel analysis. The first two components are cumulating $37.9 \%$ of the eigenvalues in the components.

The first component of roughness (1R) contains great representation with percentiles $\left(P_{5}, P_{10}, P_{50}, P_{90}\right.$ and $\left.P_{95}\right)$ with positive loadings and major findings explaining auditory descriptors with negative loadings. The second component (2R) is composed mainly of positive loadings of hypothesis (perceptual attribute and experiments), data collection (listening tests/acoustic virtual reality) and negative loadings of objective evaluations.

In the fluctuation strength PCA results, the extraction of five components represented $77.2 \%$ of the loadings extraction. Bartlett's test of sphericity was significant $\left(\chi^{2}(55)=72.483\right.$, $p<0.001)$ and $\mathrm{KMO}=0.473$, which was acceptable to proceed with the analysis. As in the sharpness PCA, all components are relevant according to the parallel analysis.

The first component of fluctuation strength (1FS) shows positive loadings for percentiles $\left(P_{10}\right.$ and $\left.P_{90}\right)$ and data collection (interviews). The second component (2FS) explains the component with positive loadings through hypothesis (experiments), data collection (listening tests/AVR). The third component (3FS) shows positive loadings of hypothesis (characterisation and dimensions). Regarding the fourth component (4FS), it shows positive loadings of percentiles $\left(P_{10^{-}}\right.$ $\left.P_{90}\right)$ and negative loadings of major findings regarding fluctuation strength (correlations physical descriptors). The fifth component (5FS) shows positive loadings of hypothesis (perceptual attributes) and data collection (questionnaire/survey).

\section{Discussion}

As observed in Annex Table 2, a few studies adopted all psychoacoustic parameters as objective descriptors [56•, 66•, $67,74 \bullet \bullet, 75]$. Some publications seem to be of particular importance due to a comprehensive data collection and rich 


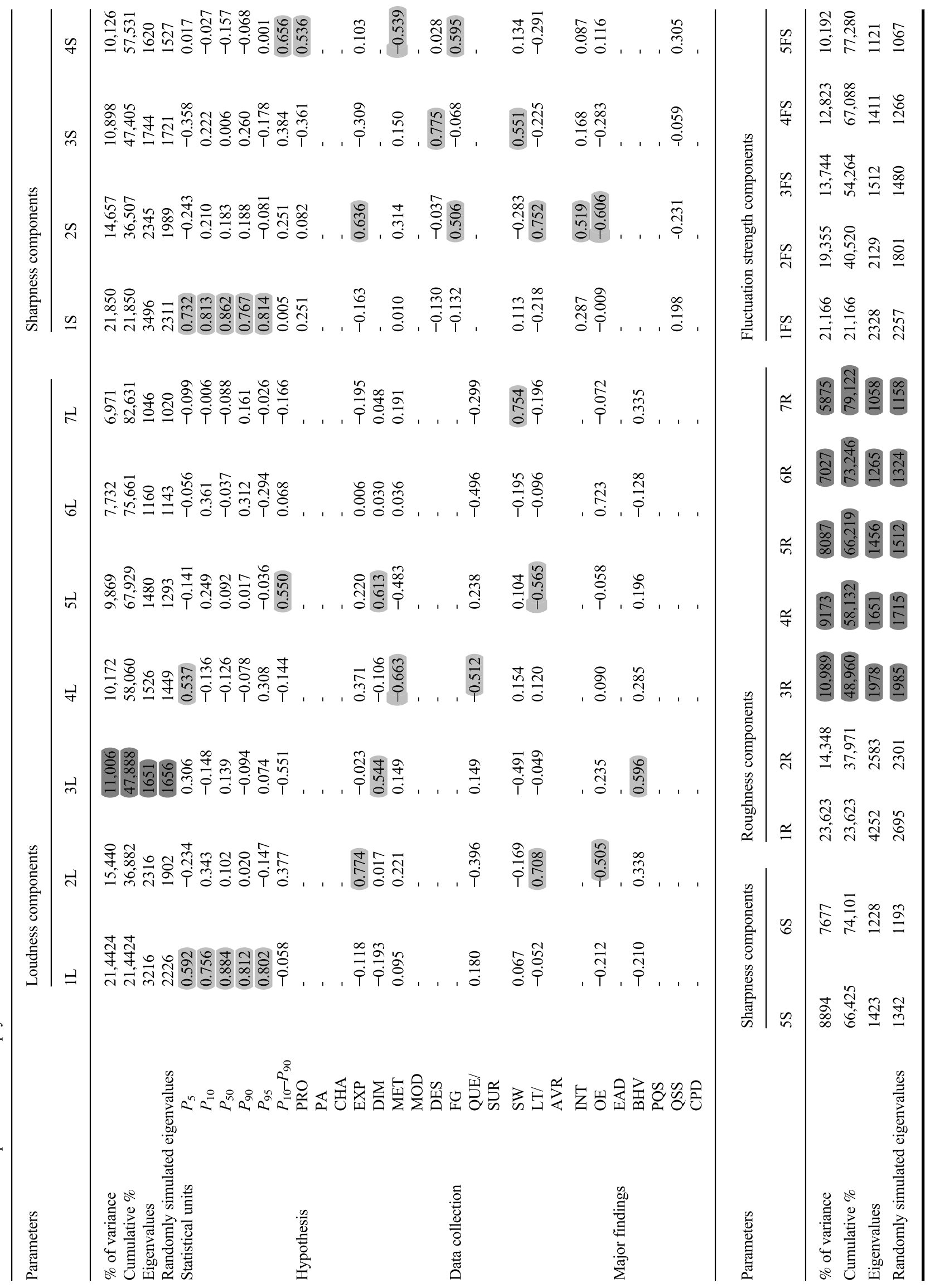




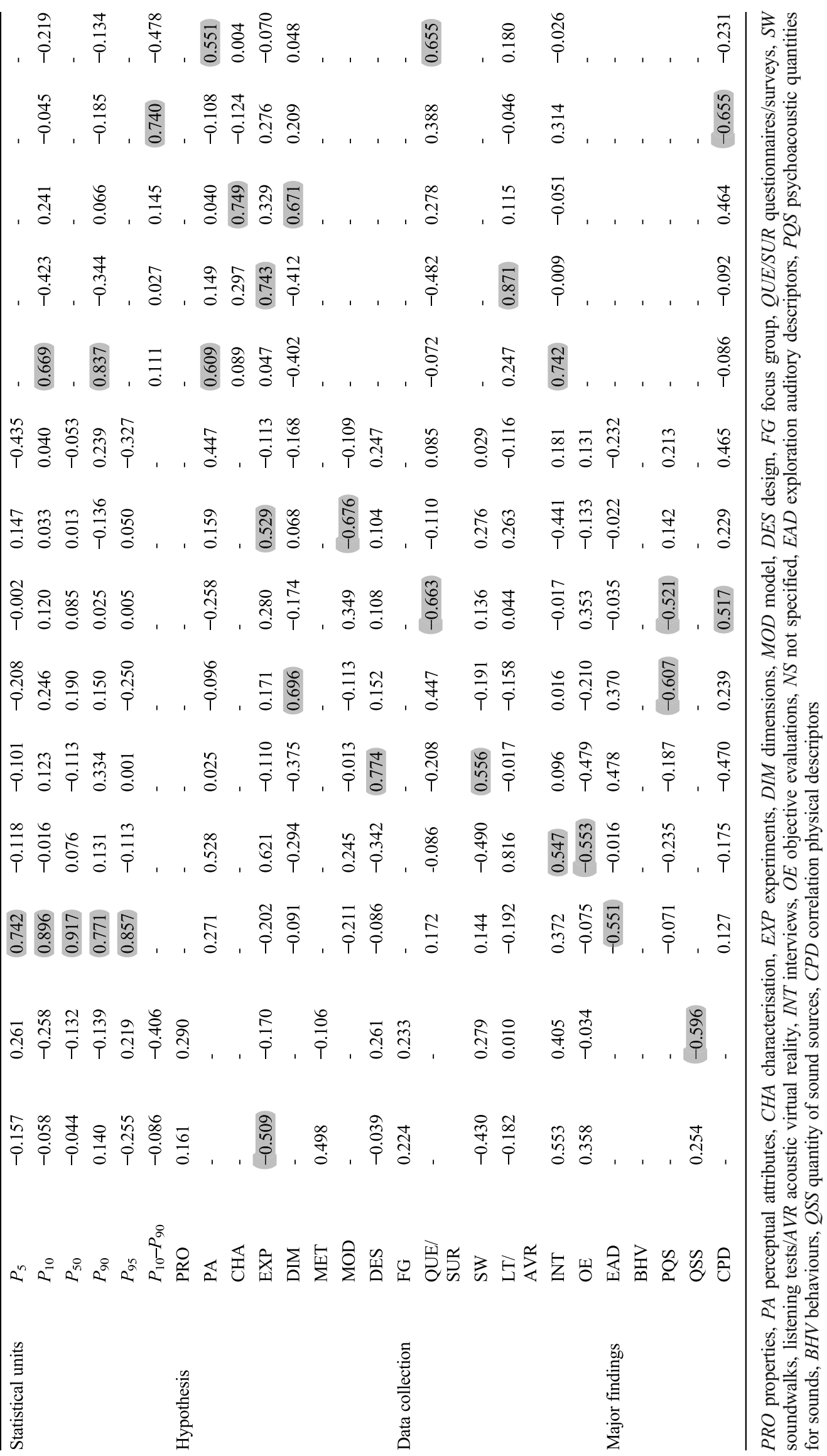


databases for soundscape analysis reflecting on psychoacoustics $[39 \bullet \bullet, 40 \bullet \bullet, 56 \bullet, 59,61 \bullet \bullet, 66 \bullet]$. Regarding the highlighted works, there are excellent examples of studies that researched soundscape quality modelling through artificial neural networks using 254 interviews [39••]; relationship between air quality and soundscape perception using 30 soundwalks [74••]; characterisation of geometrical profile and soundscape perception using 16 different listening tests [61••]; verification of perceptual attributes in sound preferences of Buddhist temples using 685 interviews [40••] and improvement of soundscape quality through experiments using 68 listening tests [59••]. Works that were characterised as of importance investigated indoor soundscapes $[40,41]$ and outdoor soundscapes [66•]. Cik et al. [66•] focused on objective measures of sound and vibration generated by trams in Graz, Austria, aiming to characterise and verify relationships and measures of this kind of sound source in urban environments. The other work that dealt with indoor soundscapes conducted 70 listening tests to confirm the importance of rolling noise of chairs in office environments [56•].

As mentioned in the introduction, the ISO 12913-2 [4] proposed psychoacoustic indicators as objective descriptors. The most used psychoacoustic indicator is Loudenss, followed by sharpness, roughness, fluctuation strength and tonality. Lionello et al. [88] also showed in their work that Loudness was the most applied indicator in soundscape model development. Still, as observed on the present work, detailed information is missing to guide the comprehensive use of these indicators in soundscape investigations (e.g. statistical units and psychoacoustic calculation methods). Indirectly, the lack of this kind of content can be observed in the hypothesis adoption in the investigations, through works that opted on the characterisation $(21.0 \%)$, relationships $(17.1 \%)$ and model construction $(10.5 \%)$ which can also be reinforced by the work of Lionello et al. [88] that indicated a vast variety of adopted approaches for the development of soundscape models. Other hypotheses such as verification of dimensions, design and methodology, which the sum was 9.5\%, are depending on well-specified conditions that could include proper statistical units and psychoacoustic calculation methods. Regarding the statistical units, it was observed that some studies used beside averages, percentiles and variability between percentiles (e.g. $P_{10}-P_{90}$ ) $[37,43,46,51,64,78,82]$, but no study found in the literature review considered the ratio between percentiles, which could explain dynamics phenomena according to Genuit and Fiebig [89]. Accordingly, the ISO/TS 12913-3 proposes the quotient of the loudness $N_{5}$ and $N_{95}$ as an indicator of the magnitude of loudness variability [90].

In several cases, a quarter of the studies, the computation method or used standard, was not specified, limiting the comparability of study results.

The stimuli classification showed a greater distribution of classes in Brown's et al. [83] taxonomy, which distributed the reported stimuli in eight classes, while Schafer's [84] taxonomy classified in five classes the same stimuli. Some classes of both taxonomies are similar, such as 'nature - natural sounds', 'social/communal - sounds and society', 'voice and instrument, human movement - human sounds' and 'electro-mechanical mechanical sounds'. Additional two classes are helping in the distribution of stimuli in Brown's taxonomy, which are 'domesticated animals' and 'others'.

From the PCA, it was possible to observe some common tendencies regarding the use of psychoacoustic indicators. The first component of the majority of the PCA's was composed using $P_{5}, P_{10}, P_{50}, P_{90}$ and $P_{95}$ (1L, $1 \mathrm{~S}$ and $1 \mathrm{R})$ with the exception of the first component of the PCA of fluctuation strength (1FS), which is showing $P_{10}$ and $P_{90}$. In the PCA of roughness (1R), the first component also presented few cases with major findings (explanation of auditory descriptors). Other components that involve percentiles are $4 \mathrm{~S}$ and $4 \mathrm{FS}$, which are presenting $P_{10}-P_{90}$. In $4 \mathrm{~S}$, they are combined with few cases investigating a methodology as a hypothesis and through focus group as data collection. The combination of percentiles differences of 4FS occurred in few cases when the major findings related to fluctuation strength found a correlation with physical descriptors. There are some patterns related to common hypothesis (experiments) and data collection method (listening test and AVR) in 2L, 2S, 2 FS and 2R. In $2 \mathrm{~S}$ and $2 \mathrm{R}$, other common data collections were interviews and few cases of objective measurements. The difference between $2 \mathrm{~S}$ and $2 \mathrm{~F}$ is that in the component with sharpness, another highlighted data collection method is a focus group. In the component with fluctuation strength, it highlighted the hypothesis about perceptual attributes. Few cases investigated experiments as hypotheses using exclusive interviews as a data collection method, as shown in 5S. Other important findings are the investigation of design through soundwalks shown in 3S; studies investigating simultaneously the characterisation and dimensions of soundscapes are shown in 3FS; investigations about perceptual attributes through questionnaires are shown in 5FS.

\section{Conclusion}

This work aimed to explore the applicability of psychoacoustic parameters in soundscape studies through a systematic review of peer-reviewed publications over the last 10 years. From the systemic review, studies have made concentrated efforts to characterise sound, create functional relationships and construct complex models with the help of psychoacoustic indicators. The 
most used indicator so far was loudness as the humanperception-based counterpart of the sound pressure level indicator, followed by sharpness, roughness and fluctuation strength and tonality.

Most of the studies use average values of the magnitude of a psychoacoustic parameter over time as a representative value of the overall impression concerning different auditory sensations. A bit more than half of the studies adopted other statistical units like percentiles and percentile differences considering cognitive effects of processing time-variant sensations as suggested in the ISO 532-1: 'Due to the fact that the statistical mean of time-varying loudness leads, in general, to results that are too low in comparison to the evaluated loudness, the percentile loudness $N_{5}$ shall be given when starting the overall loudness perceived [...]' [23]. However, it appears that the potential of adequate statistical quantities representing overall auditory impressions is not fully exploited as different kinds of mean values and ratios of single values were not frequently considered. For example, Fiebig and Sottek [91] suggested that based on mean power values of the loudness over time, the level of prominent events and background can be considered simultaneously; the weighting of these aspects depends on the applied exponent [91].

Around one quarter $(25 \%)$ of the studies did not indicate the calculation method of the psychoacoustic parameters. There was a vast distribution of the usage of diverse calculation methods for all indicators limiting the comparability and meta-analysis of soundscape studies. Some of them even seem particularly inappropriate in urban sonic environments, which was the research context of most investigated publications. This highlights the need for improved guidance from experts in psychoacoustics to soundscape researchers regarding the best practice in applying psychoacoustic parameters. The technical specifications ISO/TS 12913-2 and ISO/TS 12913-3 [4, 90] might help overcome those problems as they provide instructions on how to measure, analyse and document psychoacoustic quantities in soundscape studies.

The major findings show in few investigations related to auditory descriptors an association with percentiles $\left(P_{5}, P_{10}, P_{50}, P_{90}, P_{95}\right)$ in roughness studies, and few major findings related to correlation with physical descriptors were highlighted using $P_{10}-P_{90}$ in fluctuation strength studies. The investigation of few cases related to methodology was possible through the difference of percentiles $\left(P_{10}-P_{90}\right)$ in sharpness studies. $P_{10}$ and $P_{90}$ helped to analyse fluctuation strength in studies that used interviews as a data collection method. These findings highlight that using different statistical units can contribute to a broader understanding of the perception of the sonic environment and lead to further investigations, including verifying ratios between percentiles as a simple indicator for parameter variations. As observed in the descriptive analysis of this work, $36.5 \%$ of the investigated studies used averages of psychoacoustic parameters as singles values over time. However, this statistical unit was not highlighted as a significant parameter that could inform a trend combined with other descriptors, indicating a significant role in soundscape studies. Altogether, based on the literature review, a clear direction concerning needed percentile values corresponding to the overall impression of certain auditory sensations over time in context cannot be recognised so far, and further work appears justified.

In an overall view, this work indicates few tendencies for the use of psychoacoustic indicators on soundscape studies published in the last 10 years, which corresponds to the period where the ISO 12913 started to be in use. As expected, there is a great distribution of types of investigations, which adopt different hypotheses, data collection methods, psychoacoustic indicators, use of different computational methods to obtain the psychoacoustic indicators and adoption of statistical units, which will provide common outputs through major findings. To obtain precise tendencies, through the above-mentioned combinations of parameters and methods, it is required to publish a greater number of soundscape studies using psychoacoustic indicators in the following years.

Through the different outcomes, it will be possible to obtain a confirmation of which statistical units and which psychoacoustic indicators are properly answering the investigated hypothesis. Another possibility to obtain more precise outcomes through a systematic review using PCA as a statistical method is to focus only on one type of hypothesis, or way of data collection or expected major finding. In general, principal component analysis can find methodological patterns working well in soundscape studies, corroborating for optimisation of established standards.

Funding Open Access funding enabled and organized by Projekt DEAL. This work is funded by the Coordenação de Aperfeiçoamento de Pessoal de Nível Superior/Programa Ciências sem Fronteiras (CAPES - Brazil's National Coordination of Personal Improvement on Superior Level/ Science Without Borders Program) and the Deutscher Akademischer Austauschdienst (DAAD - German Academic Exchange Service).

\section{Compliance with Ethical Standards}

Conflict of Interest On behalf of all authors, the corresponding author states that there is no conflict of interest.

Human and Animal Rights and Informed Consent This article does not contain any studies with human or animal subjects performed by any of the authors. 


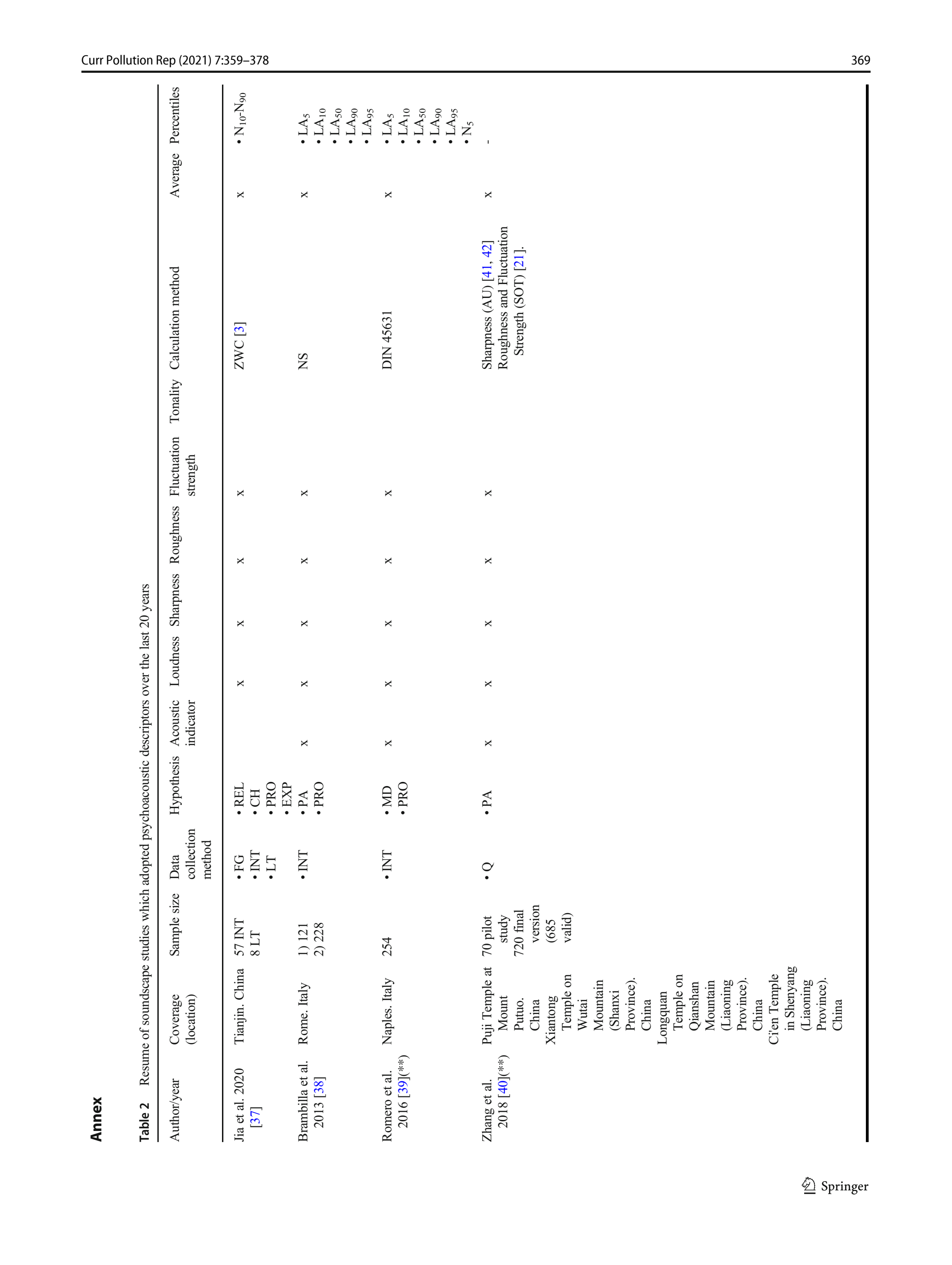




$$
11
$$




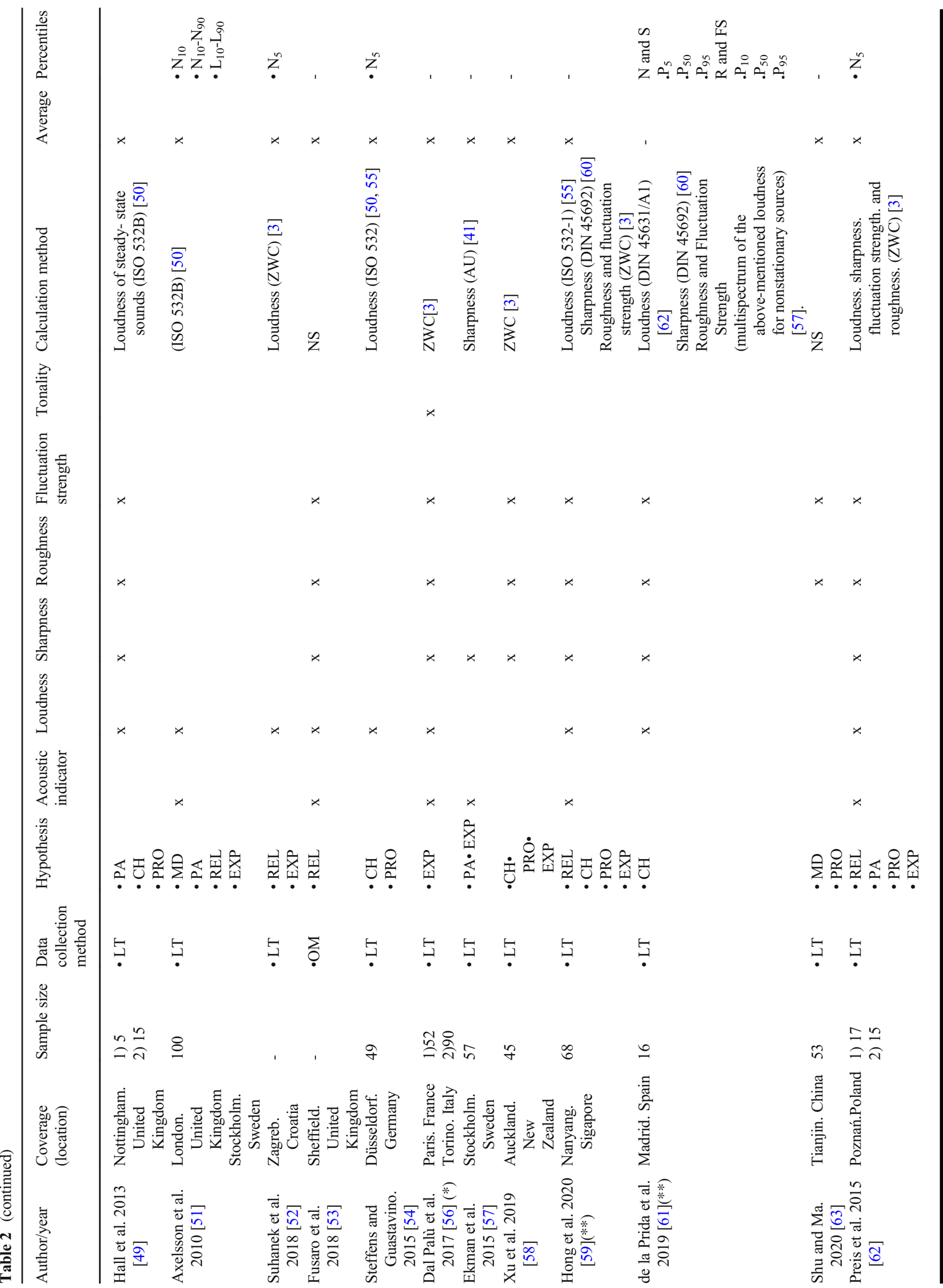




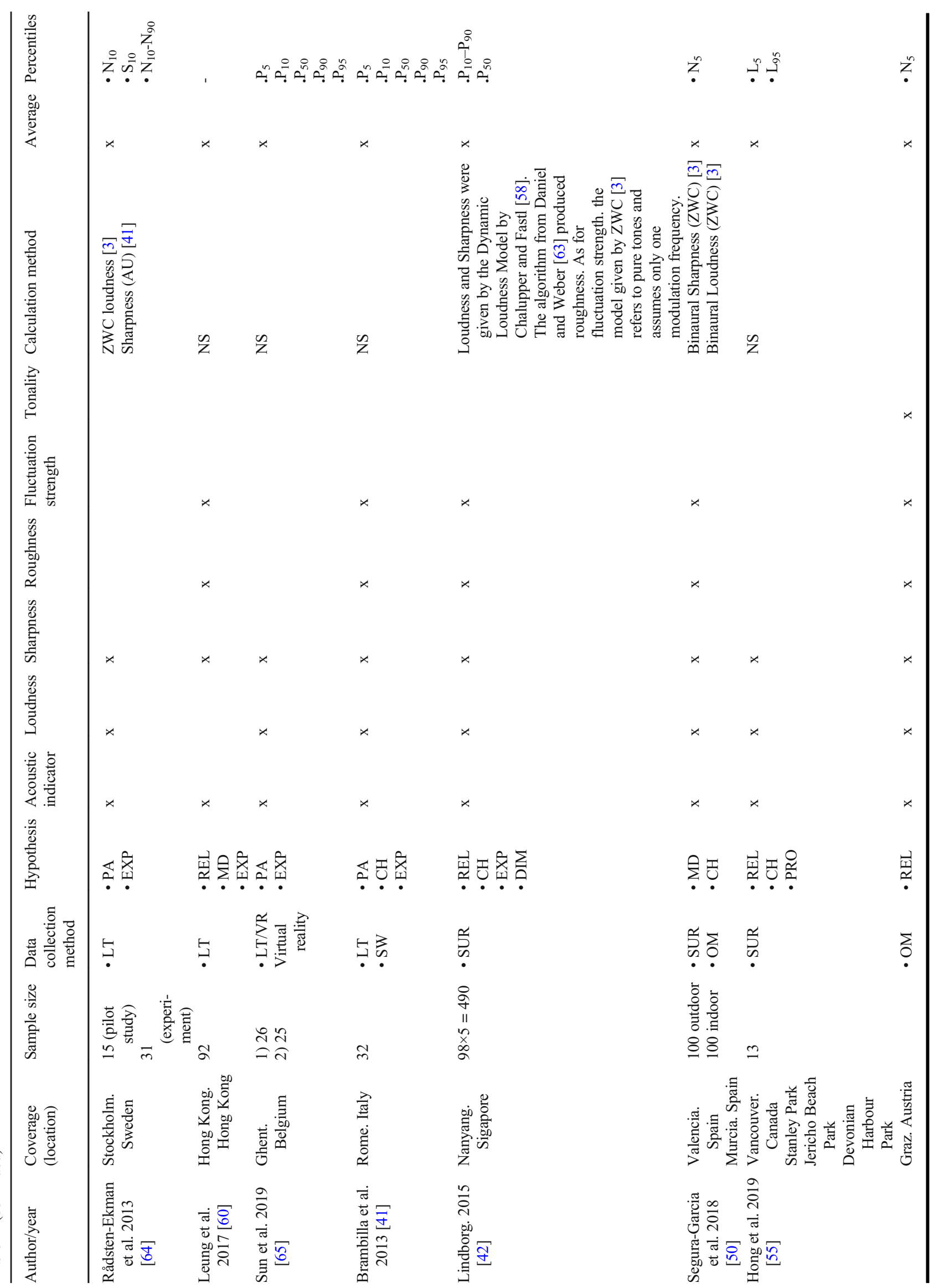




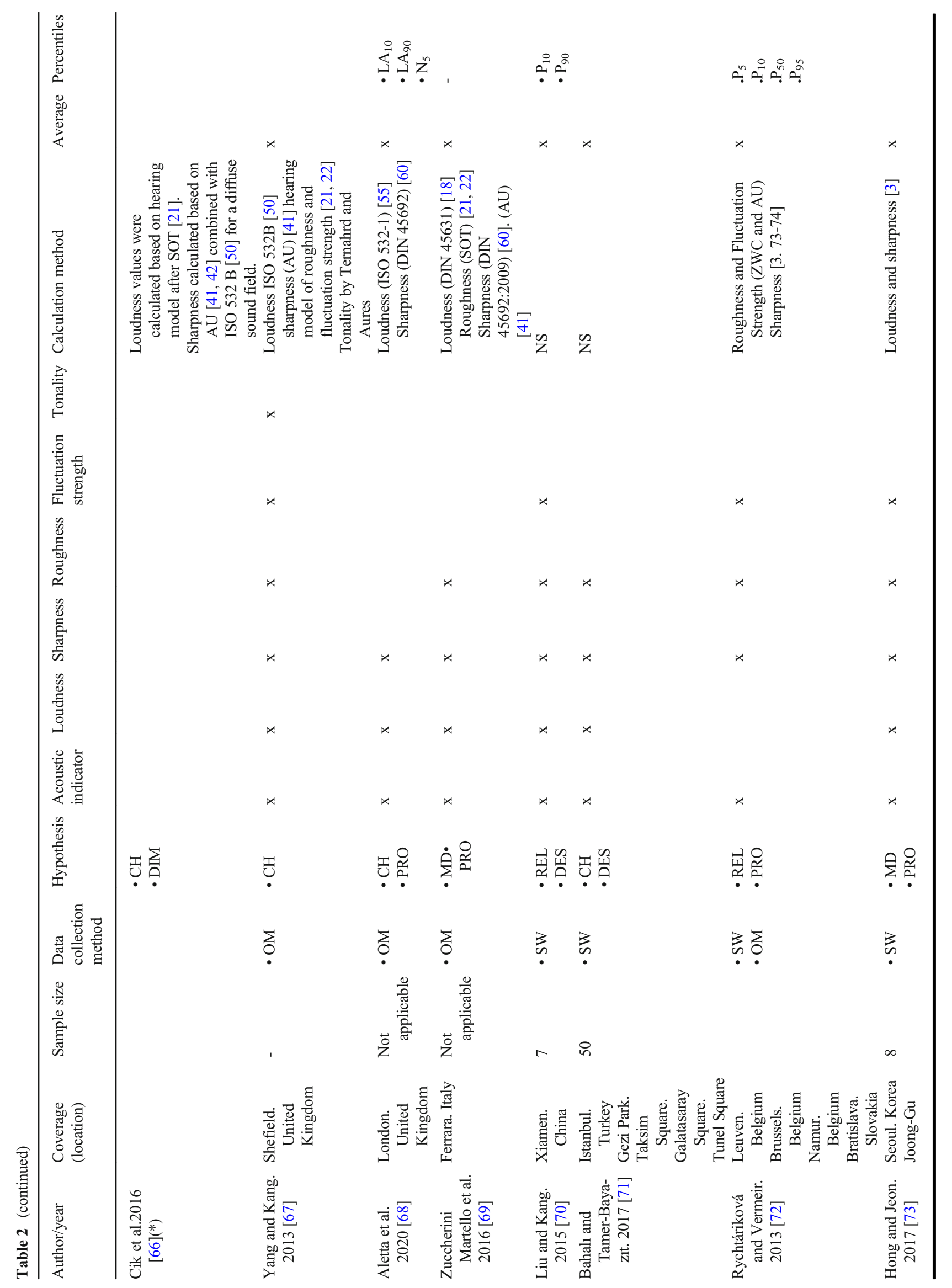




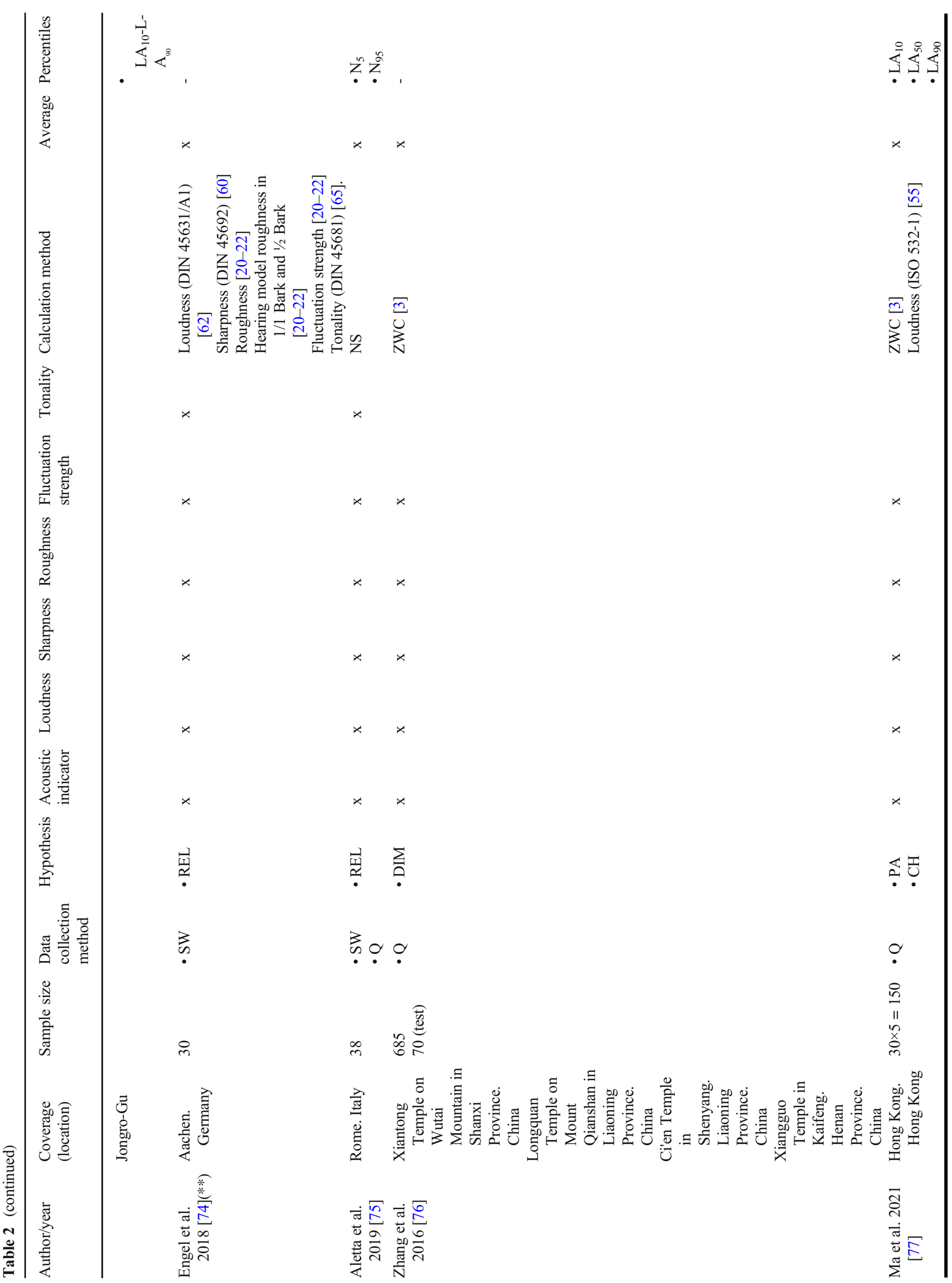




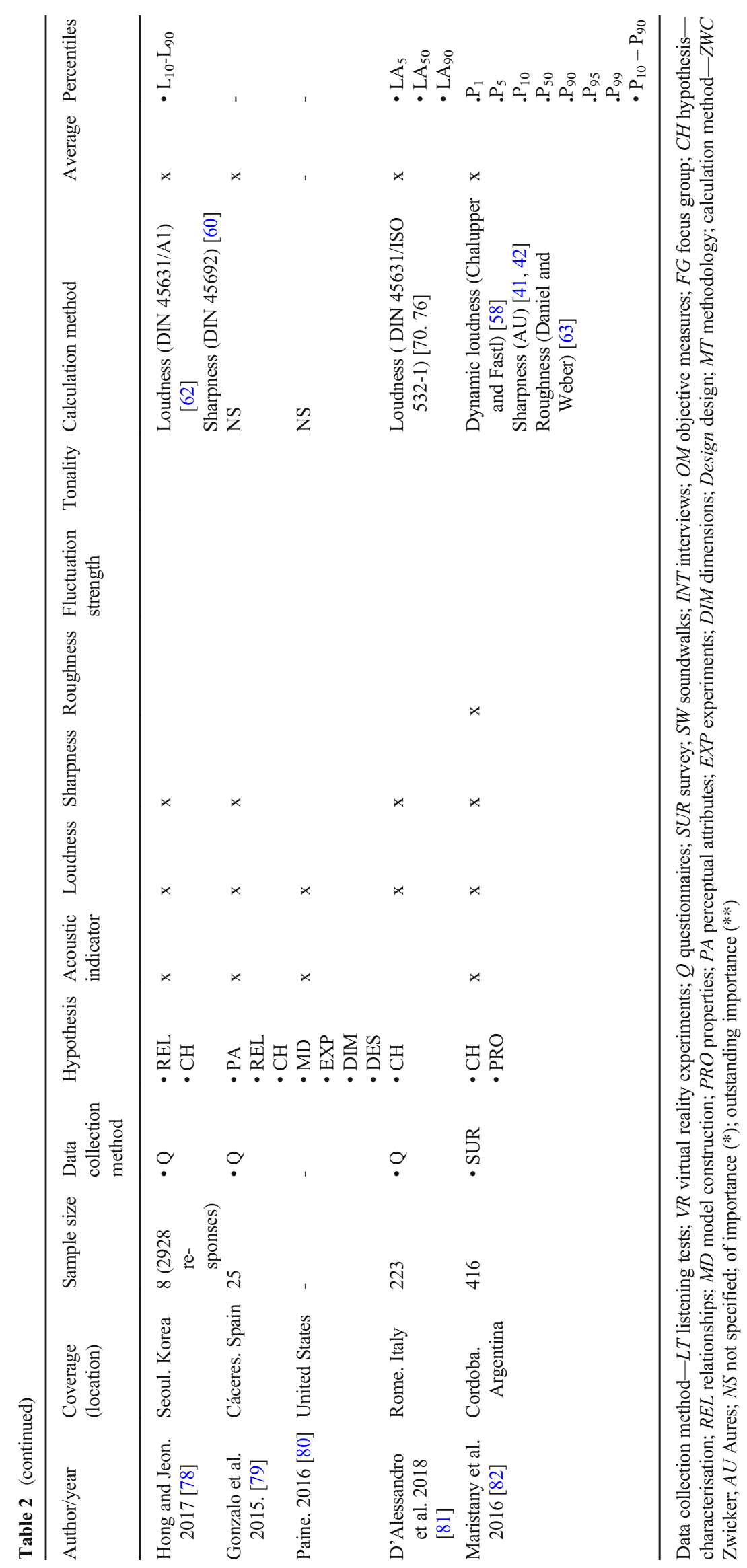


Open Access This article is licensed under a Creative Commons Attribution 4.0 International License, which permits use, sharing, adaptation, distribution and reproduction in any medium or format, as long as you give appropriate credit to the original author(s) and the source, provide a link to the Creative Commons licence, and indicate if changes were made. The images or other third party material in this article are included in the article's Creative Commons licence, unless indicated otherwise in a credit line to the material. If material is not included in the article's Creative Commons licence and your intended use is not permitted by statutory regulation or exceeds the permitted use, you will need to obtain permission directly from the copyright holder. To view a copy of this licence, visit http://creativecommons.org/licenses/by/4.0/.

\section{References}

Papers of particular interest, published recently, have been highlighted as:

- Of importance

•- Of major importance

1. Kang J, Aletta F, Gjestland TT, Brown LA, Botteldooren D, Schulte-Fortkamp B, et al. Ten questions on the soundscapes of the built environment. Building and Environment. 2016;108:284 94.

2. Welsh Government. Welsh noise and soundscape action plan 20182023, 2018. ISBN: 978-1-78964-365-7

3. Genuit K, Fiebig A. Human hearing-related measurement and analysis of acoustic environments: requisite for soundscape investigations (133-160). In: Kang J, Schulte-Fortkamp B, editors. Soundscape and the built environment. Taylor \& Francis Group, Boca Raton: CRC Press; 2016. ISBN: 978-1-4822-2631-7.

4. International Organization for Standardization. ISO/TS 12913-2: 2018 Acoustics-Soundscape-Part 2: data collection and reporting requirements. Geneva, Switzerland, 2018.

5. International Organization for Standardization. ISO 12913-1:2014. Acoustics - Soundscape - Part 1: definition and conceptual framework. Geneva, Switzerland, 2014.

6. Pulkki V, Karjalainen M. Communication Acoutics: An introduction to speech, audio and psychoacoutics. West Sussex: Wiley; 2015.

7. Lentz JJ. Psychoacoustics: perception of normal and impaired hearing with audiology applications. San Diego. CA. USA: Plural Publishing Inc.; 2020.

8. Schneider BA, Parker S. The evolution of psychophysics: from sensation to cognition and back, In: Fechner day 2010, vol. 26. B.A., Parker, S.: Schneider; 2010.

9. Gygi B, Kidd GR, Watson CS. Spectral-temporal factors in the identification of environmental sounds. J Acoust Soc Am. 2004;115:1252-65.

10. Gygi B, Kidd GR, Watson CS. Similarity and categorisation of environmental sounds. Percep Psychophys. 2007;6(6):839-53.

11. Kidd GR, Watson CS. The perceptual dimensionality of environmental sounds. Noise Control Eng J. 2003;51(4):216-31.

12. Zwicker E, Fastl H. Psychoacoutics: Facts and Models. Berlin: Springer; 2007.

13. Zeitler A., Fastl H., Hellbrück J., Thoma G., Ellermeier W., Zeller P. Methodological approaches to investigate the effects of meaning. expectations and context in listening experiments. Presented in Internoise 2006. Honolulu. HI.
14. Sköld A., Västfjäll D., Kleiner M. Perceived sound character and objective properties of powertrain noise in a car compartment. Acta Acustica United with Acustica, 2005: 91(2).

15. Schulte-Fortkamp B, Fiebig A. Impact of soundscape in terms of perception. Soundscape and the built environment. 2016:69-88.

16. Schulte-Fortkamp B, Fiebig A. Impact of soundscape in terms of perception (69-88). In: Kang J, Schulte-Fortkamp B, editors. Soundscape and the built environment. Taylor \& Francis Group, Boca Raton: CRC Press; 2016. ISBN: 978-1-4822-2631-7.

17. American National Standard. ANSI - S1.1: Acoustical Terminology. 2013

18. DIN 45631. Calculation of loudness level and loudness from the sound spectrum - Zwicker method, Berlin 1991.

19. American National Standard. ANSI/ASA S3.4-2007: Procedure for computation of loudness of steady sounds, 2007.

20. International Organization for Standardization. ISO 532B. Acoustics - methods for calculating loudness level,1975: Geneva, Switzerland.

21. International Organization for Standardization. ISO 532-2. Acoustics - methods for calculating loudness - Part 2: MorreGlasberg method. 2017: Geneva, Switzerland

22. DIN 45631/A1. Calculation of loudness level and loudness from the sound spectrum -Zwicker method - Amendment 1: Calculation of the loudness of time-variant sound, 2010: Beuth Verlag.

23. International Organization for Standardization. ISO 532-1. Acoustics - Methods for calculating loudness - Part 1: Zwicker method. International Organization of Standardization, 2017: Geneva, Switzerland

24. Psychoakustik ZE. Berlin. Heidelberg: Springer Verlag; 1982.

25. Glasberg B.R., Moore B.C. A model of loudness applicable to timevarying sounds, J. Audio Eng. Soc., Vol. 50, No. 5, 2002 May 2002.

26. Fastl H., Zwicker E. Psychoacoustics - facts and models. Springer, Berlin, Third Edition, 2007 ISBN: 978-3540688884

27. DIN 45692. Measurement technique for the simulation of the auditory sensation of sharpness, Beuth Verlag, Berlin, 2009.

28. von Bismarck G. Sharpness as an attribute of the timbre of steady sounds. In: Acustica. 1974;30:159-72.

29. Aures W. Berechnungsverfahren für den sensorischen Wohlklang beliebiger Schallsignale, Acustica. Bd. 1985;59:130-41.

30. Head Acoustics. Psychoacoustics II: Calculating psychoacoustic parameters in ArtemiS SUITE. Application Note 03/18. Available at: <https://www.head-acoustics.com/downloads/eng/application notes/Psychoacoustic_Analyses_II_e.pdf $>$ retrieved at 16th December 2020.

31. Sottek R. Modelle zur Signalverarbeitung im menschlichen Gehör. RWTH Aachen, Deutschland: Dissertation; 1993.

32. International Organization for Standardization. ISO 7729: 2010. Acoustics - measurement of airbone noise emitted by information technology and telecommunication equipments. Geneve: ISO. p. 2010.

33. Bienvenue GR, Nobile MA. Prominence ratio for noise spectra with discrete tones: a procedure based on Zwicker's critical band research. Proceedings of Inter-Noise. 1991:53-5.

34. Becker J., Sottek R., Lobato T. Progress in tonality calculation. In Proceedings of International Conference on Acoustics - ICA 2019, Aachen Germany 9-13 September 2019.

35. Johnston JD. Transform coding of audio signals using perceptual noise creteria. IEEE J. Selected Areas in Communication. 1985;6(2):314-23.

36. Moher D, Liberati A, Tetzlaff J, Altman DG, The PRISMA Group. Preferred Reporting Items for Systematic Reviews and MetaAnalyses: The PRISMA Statement. PLoS Med. 2009;6(7): e1000097. https://doi.org/10.1371/journal.pmed1000097. 
37. Jia Y, Ma H, Kang J, Wang C. The preservation value of urban soundscape and its determinant factors. Applied Acoustics. 2020;168:107430.

38. Brambilla G, Gallo V, Asdrubali F, D'Alessandro F. The perceived quality of soundscape in three urban parks in Rome. The Journal of the Acoustical Society of America. 2013;134(1):832-9.

39.• Romero VP, Maffei L, Brambilla G, Ciaburro G. Modelling the soundscape quality of urban waterfronts by artificial neural networks. Applied Acoustics. 2016;111:121-8 This is a study that is using subjective and objective measures, and is indicating which psychoacoustic standards are used for the calculation of single values.

40.• Zhang D, Zhang M, Liu D, Kang J. Sounds and sound preferences in Han Buddhist temples. Building and Environment. 2018;142: 58-69 This is a study that is using subjective and objective measures, and is indicating which psychoacoustic standards are used for the calculation of single values.

41. Brambilla G, Maffei L, Di Gabrielle M, Gallo V. Merging physical parameters and laboratory subjective ratings for the soundscape assessment of urban square. The Journal of the Acoustical Society of America. 2013;134(1):782-90.

42. Lindborg P. Psychoacoustic. physical. and perceptual features of restaurants: a field survey in Singapore. Applied Acoustics. 2015;92:47-60.

43. Aletta F, Kang J. Towards an urban vibrancy model: a soundscape approach. International Journal of Environmental Research and Public Health. 2018;15(8):1712.

44. Yu B, Kang J, Ma H. Development of indicators for the soundscape in urban shopping streets. Acta Acustica United with Acustica. 2016;102(3):462-73.

45. Yu L, Kang J. Using ANN to study sound prefernce evaluation in urban open spaces. Journal of Env Eng and Landscape Management. 2015;23(3):163-71.

46. Linborg P, Friberg A. Personality traits bias the perceived quality of sonic environments. Applied Sciences. 2016;6(12):405.

47. Çakir DA, Yimaz S. Assessment of sound enviornment pleasantness by sound quality metrics in urban spaces. ITU Journal of the Faculty of Architecture. 2016;13(2):87-99.

48. Fan J, Thorogood M, Pasquier P. Automatic soundscape affect recognition using a dimensional approach. Journal of the Audio Engineering Society. 2016;64(9):646-53.

49. Hall DA, Irwin A, Edmondson-Jones M, Poxon S, John EW. An exploratory evaluation of perceptual. psychoacoustic and acoustical properties of urban soundscapes. Applied Acoustics. 2013;74:24854.

50. Segura-Garcia J, Navarro-Ruiz JM, Perez-Solano JJ, MontoyaBelmonte J, Felici-Castell S, Cobos M, et al. Spatio-temporal analysis of urban acoustic environments with binaural psychoacoustical considerations for IoT-based applications. Sensors. 2018;18(3):690.

51. Axelsson Ö, Nilsson ME, Berglund B. A principal components model of soundscape perception. The Journal of the Acoustical Society of America. 2010;128(5):2836-46.

52. Suhanek M, Djurek I, Grubeša S, Petošić A. Psychoacoustical approach in soundscape characterization. Advances in Science. Technology and Engineering Systems Journal. Special Issue on Multidisciplinary Sciences and Engineering. 2018;3(4):211.

53. Fusaro G, D'Alessandro F, Baldinelli G, Kang J. Design of urban furniture to enhance the soundscape: a case study. Building Acoustics. 2018;25(1):61-75.

54. Steffens J, Guastavino C. Trend. Effects in momentaryand retrospective soundscape judgments. Acta Acustica united with Acustica. 2015;101(4):713-22.

55. Hong X, Wang G, Liu J, Lan S. Cognitive persistence of soundscape in urban parks. Sustainable Cities and Society. 2019;51: 101706.
56. Dal PD, Buiatti E, Puglisi GE, Houix O, Susini P, de Giogi C, et al. The use of semantic differential scales in listening tests: a comparison between context and laboratory test conditions for the rolling sounds of office chairs. Applied Acoustics. 2017;127:270-83 Listening test which used Tonality as one of the psychoacoustic indicators.

57. Ekman MR, Lundén P, Nilsson ME. Similarity and pleasantness assessments ofwater-fountain sounds recorded in urban public spaces. The Journal of the Acoustical Society of America. 2015;138(5):3043-52.

58. Xu Y, Hamid N, Shepherd D, Kantono K, Reay S, Martinez G, et al. Background soundscapes influence the perception of icecream as indexed by electrophysiological measures. Food Research International. 2019;125:108564.

59.• Hong JY, Ong Z, Lam B, Ooi K, Gan W, Kang J, et al. Effects of adding natural sounds to urban noises on the perceived loudness of noise and soundscape quality. Science of the Total Environment. $2020 ; 711: 134571$ This is a study that is using subjective and objective measures, and is indicating which psychoacoustic standards are used for the calculation of single values.

60. Leung TM, Chau CK, Tang SK, Xu JM. Developing a multivariate model for predicting the noise annoyance responses due to combined water sound and road traffic noise exposure. Applied Acoustics. 2017;127:284-91.

61.• de La Prida D, Pedrero A, Navacerra MA, Diaz C. Relationship between the geometric profile of the city and the subjective perception of urban soundscapes. Applied Acoustics. 2019;149:74-84 This is a study that is using subjective and objective measures, and is indicating which psychoacoustic standards are used for the calculation of single values and percentiles.

62. Preis A, Kociński J, Hafke-Dys H, Wrzoske M. Audio-visual interactions in environment assessment. Science of the Total Environment. 2015;523:191-200.

63. Shu S, Ma H. Restorative effects of urban park soundscapes on children's psychophysiological stress. Applied Acoustis. 2020;164:107293.

64. Rădsten-Ekman M, Axelsson Ö, Nilsson ME. Effects of sounds from water on perception of acoustic environments dominated by road-traffic noise. Acta Acustica united with Acustica. 2013;99(2): 218-55.

65. Sun K, De Coensel B, Filipan K, Aletta F, van Renterghem T, De Pessemier T, et al. Classification of soundscapes of urban public open spaces. Landscape and Urban Planning. 2019;189:139-55.

66. Cik M, Lienhart M, Lercher P. Analysis of psychoacoustic and vibration-related parameters to track the reasons for health complaints after the introduction of new tramways. Applied Sciences. 2016;6(12):398 This is a study that is using objective measures, and adopted Tonality as one of the psychoacoustic indicators.

67. Yang M, Kang J. Psychoacoustical evaluation of natural and urban sounds in soundscapes. The Journal of the Acoustical Society of America. 2013;134(1):840-51.

68. Aletta F, Oberman T, Mitchell A, Tong H, Kang J. Assessing the changing urban sound environment during the COVID-19 lockdown period using short-term acoustic measurements. Noise mapping. 2020;7(1):123-34.

69. Zuccherini NM, Aletta F, Fausti P, Kang J, Secchi S. A psychoacoustic investigation on the effect of external shading devices on building facades. Applied Sciences. 2016;6(12):429.

70. Liu J, Kang J. Soundscape design in city parks: exploring the relationships between soundscape composition parameters and physical and psychoacoustic parameters. Journal of Enviornmental Engineering and Landscape Management. 2015;23(2):102-12.

71. Bahalı S, Tamer-Bayazit N. Soundscape research on the Gezi Park - Tunel Square route. Applied Acoustics. 2017;116:260-70. 
72. Rychtáriková M, Vermeir G. Soundscape categorisation on the basis of objective acoustical parameters. Applied Acoustics. 2013;74(2):240-7.

73. Hong JY, Jeon JY. Exploring spatial relationships among soundscape variables in urban areas: a spatial statistical modelling approach. Landscape and Urban Planning. 2017;157:352-64.

74.• Engel MS, Paas B, Schneider C, Pfaffenbach C, Fels J. Perceptual studies on air quality and sound through urban walks. Cities. 2018;83:173-85 This is a study that is using subjective and objective measures, and is indicating which psychoacoustic standards are used for the calculation of single values.

75. Aletta F, Guattari C, Evangilisti L, Asdruballi F, Oberman T, Kang J. Exploring the compatibility of "Method A" and "Method B" data collection protocols reported in the ISO/TS 12913-2:2018 for urban soundscape via a soundwalk. Applied Acoustics. 2019;155:190203.

76. Zhang D, Zhang M, Liu D, Kang J. Soundscape evaluation in Chinese Buddhist temples. Applied Acoustics. 2016;111:188-97.

77. Ma KW, Mak CM, Wong HM. Effects of environmental sound quality on soundscape preference in a public urban space. Applied Acoustics. 2021;171:107570.

78. Hong JY, Jeon JY. Relationship between spatiotemporal variability of soundscape and urban morphology in a multifunctional urban area: a case study in Seoul. Korea. Building and Environment. 2017;126:382-95.

79. Gonzalo GR, Carmona JT, Barrigón Morillas JM, Vilchez-Gómes $\mathrm{R}$, Gómes EV. Relationship between objective acoustic indices and subjective assessments for the quality of soundscapes. Applied Acoustics. 2015;97:1-10.

80. Paine G. Ecologies of Listening and Presence: Perspectives from a Practitioner. Contemporary Music Review. 2016;35(3):362-71.

81. D'Alessandro F, Evangelisti L, Guatarri C, Grazieschi G, Orsini F. Influence of visual aspects and other features on the soundscape assessment of a university external area. Building Acoustics. 2018;25(3):199-217.

82. Maristany A, López MR, Rivera CA. Soundscape quality analysis by fuzzy logic: a field study in Cordoba. Argentina. Applied Acoustics. 2016;111:106-15.

83. Brown AL, Kang J, Gjestland T. Towards standardisation in soundscape preference assessment. Appl. Acoust. 2011;72(6):387-92.

84. Schafer $\mathrm{M}$. The soundscape our sonic environment and the tunning of the world. Rochester, Vermont: Destiny Books; 1994.

85. Engel MS, Fiebig A, Pfaffenbach C, Fels J. A review of socioacoustic surveys for soundscape studies. Current Pollution Reports. 2018;4(3):220-39.

86. Vivek H. P., Surendra N. S., Mishra S., Donavan D. T. Parallel analysis engine to aid in determining number of factors to retain using R [Computer software], 2017 available from https://analytics. gonzaga.edu/parallelengine/.

87. Horn JL. A rationale and test for the number of factors in factor analysis. Psychometrika. 1965;30:179-85.

88. Lionello M, Aletta F, Kang J. A systematic review of prediction models for the experience of urban soundscapes. Applied Acopustics. 2020;170:107479.

89. Genuit K, Fiebig A. The acoustic description of patterns in soundscapes, Internoise. In: Proceedings. Turkey: Istanbul; 2007.

90. International Organization for Standardization. ISO/TS 12913-3: 2019 Acoustics-Soundscape-Part 3: data analysis. Geneva, Switzerland, 2019.

91. Fiebig A, Sottek R. Contribution of peak events to overall loudness. Acta Acustica united with Acustica. 2015;101(6):1116-29.

Publisher's Note Springer Nature remains neutral with regard to jurisdictional claims in published maps and institutional affiliations. 